\title{
The basolateral amygdala is necessary for the encoding and the expression of odor memory
}

\author{
Yannick Sevelinges, Bertrand Desgranges, and Guillaume Ferreira ${ }^{1}$ \\ Laboratoire de Comportement, Neurobiologie et Adaptation, CNRS UMR6175, INRA UMR85, Université Tours, \\ F-37380 Nouzilly, France
}

\begin{abstract}
Conditioned odor avoidance (COA) results from the association between a novel odor and a delayed visceral illness. The present experiments investigated the role of the basolateral amygdala (BLA) in acquisition and retrieval of COA memory. To address this, we used the $\mathrm{GABA}_{\mathrm{A}}$ agonist muscimol to temporarily inactivate the BLA during COA acquisition or expression. BLA inactivation before odor-malaise pairing greatly impaired COA tested $3 \mathrm{~d}$ later. In contrast, muscimol microinfusion between odor and malaise spared retention. Moreover, inactivation of the BLA before pre-exposure to the odor prevented latent inhibition of COA. This suggests that neural activity in the BLA is essential for the formation of odor representation. BLA inactivation before the retrieval test also blocked COA memory expression when performed either $3 \mathrm{~d}$ (recent memory) or $28 \mathrm{~d}$ (remote memory) after acquisition. This effect was transitory as muscimol-treated animals were not different from controls during the subsequent extinction tests. Moreover, muscimol infusion in the BLA neither affected olfactory perception nor avoidance behavior, and it did not induce a statedependent learning. Altogether, these findings suggest that neural activity in the BLA is required for the encoding and the retrieval of odor memory. Moreover, the BLA seems to play a permanent role in the expression of COA.
\end{abstract}

Considerable evidence indicates that the amygdala, and more particularly, the basolateral nucleus of the amygdala (BLA), is necessary for aversive and emotional memories in rats and humans (for reviews, see McGaugh 2004; Phelps and LeDoux 2005). Numerous studies suggest that the BLA is involved in the formation of affective memory, but whether the amygdala stores such memory is controversial. Results of studies using fear conditioning support the view that essential aspects of learning take place in the BLA, which subserves long-term storage of fear memory (for review, see Phelps and LeDoux 2005). In particular, lesion studies showed that the BLA has a permanent role in the expression of learned fear (Maren et al. 1996; Gale et al. 2004). On the other hand, it has been suggested for inhibitory avoidance that the BLA is not the site of memory storage, but rather a region that is only temporarily required after training (for review, see McGaugh 2004). Consistent with this idea, the BLA is important for recent (1 d) but not for remote ( $>10$ d) memory retrieval of inhibitory avoidance (Liang et al. 1982, 1996; Izquierdo et al. 1997).

The importance of BLA has also been investigated in conditioned taste avoidance (CTA) and conditioned odor avoidance (COA), in which animals learn to avoid a taste or an odor, respectively (the conditioned stimulus, CS), previously paired with a visceral malaise (the unconditioned stimulus, US) (for reviews, see Garcia et al. 1985; Bures 1998; Batsell and Blankenship 2002). Taste was long considered the critical CS for food avoidance in comparison to odor (Palmerino et al. 1980; Garcia et al. 1985). However, it has been demonstrated more recently that when odor is mixed with water (inducing primarily retronasal detection), instead of being delivered close to the solution (inducing only orthonasal detection), odor is as effective as taste for illness: It requires a single trial, resists a CS-US delay of several hours, and can be recalled several weeks after acquisition (Slotnick et al. 1997; Chapuis et al. 2007a). Lesion or pharmacological manipulation of the BLA impaired CTA acquisition and recent memory retrieval

\footnotetext{
'Corresponding author.
}

E-mail ferreira@tours.inra.fr; fax 33-2-47-42-77-43.

Article is online at http://www.learnmem.org/cgi/doi/10.1101//m.1247609.
(Gallo et al. 1992; Yamamoto et al. 1995; Morris et al. 1999; Yasoshima et al. 2000), however, the exact role of amygdala in CTA, still remains to be solved (for reviews, see Lamprecht and Dudai 2000; Reilly and Bornovalova 2005). Concerning COA, lesion or reversible inactivation of the entire amygdala before COA impaired acquisition (Bermudez-Rattoni et al. 1983, 1986), while pharmacological stimulation of the BLA immediately after the CS presentation enhanced the COA acquisition (Ferry and Di Scala 1997). These results were based on orthonasal perception (odor on a disc), and it has to be evaluated whether similar findings can be obtained with COA based on retronasal perception (ingested odor). Moreover, these studies point to the importance of the BLA in COA memory formation; however, no evidence to date allows us to differentiate the role of the BLA in the different mnemonic phases, i.e., CS processing, US processing, or CS-US association. It remains to be established whether post-CS inactivation induced similar COA impairment as pre-CS inactivation and whether BLA neural activity is also necessary for the encoding of a nonassociative odor memory. Furthermore, it has to be elucidated whether the BLA is essential for retrieval of recent and remote COA memory in order to evaluate whether this area plays a temporary or permanent role in the expression of COA.

For this purpose, we first evaluated the effect of temporary inactivation of the BLA on acquisition of COA (based on ingested odor) by local infusions of the $\mathrm{GABA}_{\mathrm{A}}$ agonist muscimol (Mus) either before odor-malaise pairing (pre-CS) or between odor and malaise (post-CS). To further investigate the role of the BLA in the encoding of odor memory, the BLA was inactivated before exposure to ingested odor in an incidental learning. Finally, we assessed the effect of BLA inactivation on the retrieval of recent $(3 \mathrm{~d})$ and remote $(28 \mathrm{~d})$ COA memory.

\section{Results}

Inactivation of the BLA blocks the acquisition of new odor memory

We first evaluated in which stage of COA acquisition the BLA is involved. For this purpose, rats were implanted with bilateral 
cannulae in the BLA. There was no difference between groups during the days of water baseline $\left(F_{(3,42)}=2.8, P>0.05\right.$; mean water intake: $13.9 \pm 0.3 \mathrm{~mL}$ ). On the day of $\mathrm{COA}$ acquisition, all rats drank at least nine of the $10 \mathrm{~mL}$ of almond-scented water proposed $\left(0.01 \%\right.$ benzaldehyde mixed with water; $\left.F_{(3,42)}<1\right)$. Thirty minutes later they were injected intraperitoneally with the malaise-inducing agent lithium chloride ( $\mathrm{LiCl})$. Four groups of rats were tested. They received bilateral BLA injections of saline (Sal, $0.25 \mu \mathrm{L} /$ side) or Mus $(0.25 \mu \mathrm{g} / 0.25 \mu \mathrm{L} /$ side) either before (preCS groups; Sal, $n=14$; Mus, $n=14$ ) or immediately after almondscented water presentation (post-CS groups; Sal, $n=7$; Mus, $n=11$; Fig. 1A). During the next $2 \mathrm{~d}$, all groups showed normal water consumption (data not shown). Figure $1 \mathrm{~B}$ shows the percentage of scented water intake during the test day with respect to the baseline water intake. A two-way ANOVA (treatment $\times$ time of injection) revealed a significant effect of treatment $\left(F_{(1,42)}=6.5\right.$, $P=0.01)$, of time of injection $\left(F_{(1,42)}=9.7, P<0.01\right)$, and interaction $\left(F_{(1,42)}=5.9, P<0.05\right)$. Fisher's post-hoc tests revealed that only pre-CS inactivation of the BLA impaired COA acquisition $(P<0.001)$, whereas post-CS inactivation of the BLA did not have any effect.

In order to prove that BLA inactivation interferes with the odor-encoding rather than with odor-malaise association, we isolate, in time, the exposure to a novel odor from the association of this odor with a salient external reinforcer using the latent inhibition (LI) paradigm. LI is the attenuation of learning due to nonreinforced presentation of the prospective CS before CS-US pairing (Merhav and Rosenblum 2008). Because no previous data used odor input as CS in LI paradigm, we first developed LI of COA. Two groups of intact animals (i.e., not cannulated) were preexposed to zero (COA group, $n=10$ ) or $10 \mathrm{~mL}$ of almond scented water (LI group, $n=8$ ), $2 \mathrm{~d}$ before COA acquisition to the same odor. Moreover, to examine whether BLA activation is necessary for odor memory formation, animals received an intra-BLA
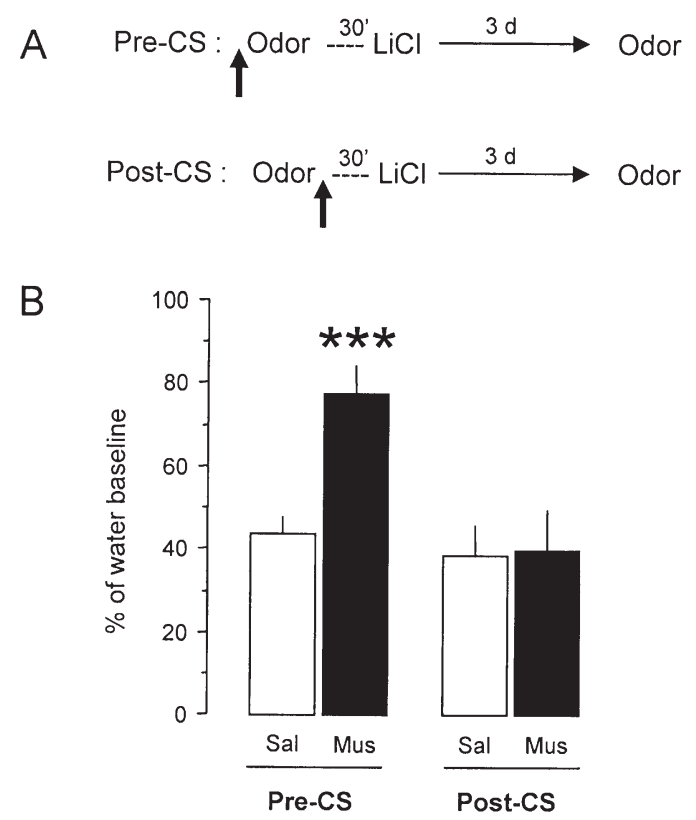

Figure 1. Effects of intra-BLA muscimol (Mus) infusion either before the presentation of the CS (pre-CS) or between CS and US (post-CS) on conditioned odor avoidance (COA) learning. (A) Schematic representation of the time of injection, COA acquisition, and memory test. (B) Behavioral results of pre-CS (left) and post-CS infusion (right) in the BLA. Note that only pre-CS Mus infusion in the BLA impaired COA learning. $\left.{ }^{* * *}\right)$ Significantly different from the other groups $(P<0.001)$. infusion $30 \mathrm{~min}$ before pre-exposure to $10 \mathrm{~mL}$ of the scented solution (LI-Sal, $n=6$; LI-Mus, $n=5$; Fig. $2 \mathrm{~A}$ ). We predicted that BLA inactivation would disrupt LI, and consequently, COA would not be weakened. There was no difference between groups during the days of water baseline $\left(F_{(3,25)}=2.3, P>0.05\right.$; mean water intake: $18.4 \pm 0.4 \mathrm{~mL}$ ). On the day of pre-exposure, all rats drank at least nine of the $10 \mathrm{~mL}$ of liquid proposed (water or scented water), and on the day of COA acquisition, all rats drank at least nine of the $10 \mathrm{~mL}$ of scented water proposed $\left(F_{(3,25)}<1\right)$. During the retention test carried out 3 d later, one-way ANOVA revealed a significant group effect $\left(F_{(3,25)}=8.3, P<0.001\right)$. Fisher's post-hoc tests revealed that the LI group showed a significantly lower aversion than the COA group $(P<0.01)$, thus indicating that pre-exposure to scented water weakened the COA (Fig. 2B). The LIMus group behaved like COA rats $(P=0.16)$ and showed a higher aversion compared with the LI-Sal and LI groups $(P<0.05)$, which did not differ from each other $(P=0.24)$. The strong and similar aversion of COA and LI-Mus groups indicated that LI-Mus animals were amnesic to the prior exposure to the odor. Altogether, these results indicate that BLA activation is necessary for the encoding of a new odor memory.

To rule out the possibility that the observed deficit was due to impairment of odor detection, we used an olfactory test based on the natural tendency of naïve rats with normal odor perception to prefer water over novel scented water (Bailey and Westbrook 2007; Desgranges et al. 2008; Sevelinges et al. 2009). For this purpose, naïve rats were infused either with Mus or Sal into the BLA 30 min before a two-choice test between water and almond-scented water ( $0.01 \%$ benzaldehyde mixed with water; Sal, $n=6$; Mus, $n=7$ ). Each group drank significantly more water than scented water (paired $t$-test; $t_{(5)}=3.3$ and $t_{(6)}=7.8$ for Sal and Mus groups, respectively, $P<0.05$ for both groups). Intergroup comparisons did not reveal significant differences for consumption of water (Sal: $14.0 \pm 1.5 \mathrm{~mL}$; Mus: $12.7 \pm 0.9 \mathrm{~mL}$; unpaired $t$-test, $\left.t_{(11)}<1\right)$ and scented water (Sal: $3.9 \pm 1.6 \mathrm{~mL}$; Mus: $2.7 \pm 0.6 \mathrm{~mL} ; t_{(11)}<1$ ). Therefore, BLA inactivation with Mus did not change naïve preference for water over almond-scented water.

\section{Inactivation of the BLA blocks the expression of recent and remote COA memory}

In order to evaluate whether the BLA is involved in odor memory retrieval, this structure was inactivated $30 \mathrm{~min}$ before either the recent ( $3 \mathrm{~d}$; Sal, $n=5$; Mus, $n=6$ ) or the remote memory test ( $28 \mathrm{~d}$; Sal, $n=7$; Mus, $n=9$; Fig. 3A). There was no difference between groups during the days of water baseline $\left(F_{(3,23)}=2.1, P>0.05\right.$; mean water intake: $15.1 \pm 0.6 \mathrm{~mL}$ ). On the day of COA acquisition, all rats drank at least nine of the $10 \mathrm{~mL}$ of scented water proposed $\left(F_{(3,23)}<1\right)$. During the retention test of COA, a two-way ANOVA (treatment $\times$ time of test) revealed a significant effect of treatment $\left(F_{(1,23)}=98.8, P<0.001\right)$, no effect of time $\left(F_{(1,23)}=1.0\right.$, $P=0.32$ ), and a significant interaction between time and treatment $\left(F_{(1,23)}=5.6, P<0.05\right)$. Fisher's post-hoc tests revealed that functional inactivation of the BLA impaired both recent and remote COA memory expression compared with saline groups $(P<0.001)$, which were not different from each other $(P=0.32$; Fig. 3B). Moreover, Mus effect was stronger for remote memory than for recent memory expression $(P<0.05)$. To verify that Mus infusion did not induce a general liquid overconsumption, all animals received $15 \mathrm{~min}$ of plain water immediately after CS presentation. Mus groups drank significantly less water than Sal groups, resulting in a similar total consumption in all groups $(\mathrm{CS}+$ water; mean total intake: $\left.17.2 \pm 0.5 \mathrm{~mL} ; F_{(3,23)}=2.2, P=0.13\right)$.

Animals of the recent and remote groups received two additional days of extinction without drug microinfusion into the BLA to determine whether Mus induced a permanent impairment 


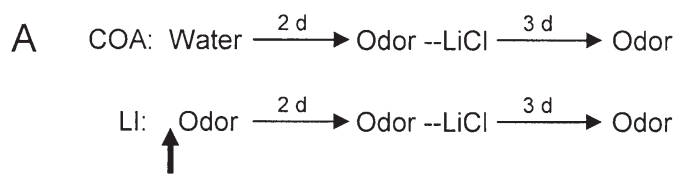

B

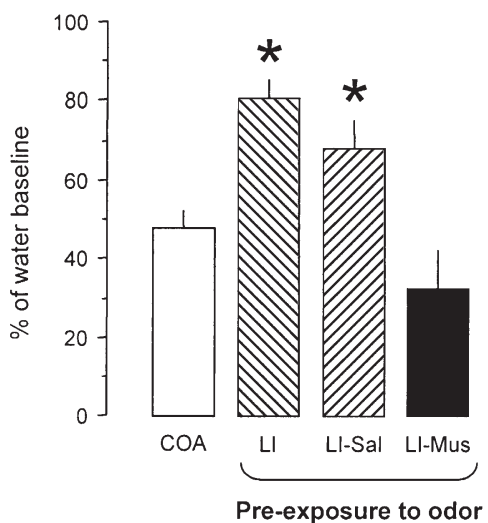

Figure 2. Effects of intra-BLA Mus infusion before pre-exposure to the CS in a latent inhibition (LI) paradigm. (A) Schematic representation of the time of injection, pre-exposure to the CS, COA acquisition, and memory test. (B) Behavioral results of nonoperated animals with no preexposure (COA group) or pre-exposure to the CS (LI group) and operated animals with intra-BLA infusion of saline (LI-Sal group) or Mus (LI-Mus) before the pre-exposure to the CS. Note that pre-exposure to the CS impaired COA learning, whereas Mus inactivation before pre-exposure prevented this impairment. (*) Significantly different from COA and LIMus groups $(P<0.05)$.

or a transient retrieval deficit. A repeated measure ANOVA (treatment $x$ three extinction tests) revealed a significant interaction of treatment and extinction tests in both recent $\left(F_{(2,18)}=\right.$ $4.5 ; P=0.03$; Fig. $3 \mathrm{C})$ and remote groups $\left(F_{(2,23)}=39.8 ; P<0.001\right.$; Fig. 3D). While the Sal groups gradually extinguished (paired $t$-test; T1 vs. T2: recent: $t_{(4)}=-3.3, P=0.03$; remote: $t_{(6)}=4.6, P<$ 0.01; T2 vs. T3: recent: $t_{(4)}=-2.4, P=0.08$; remote: $t_{(6)}=2.6, P<$ $0.05)$, the Mus groups had a different pattern: In the second test there was an increased aversion compared with the first test (T1 vs. T2: recent: $t_{(5)}=2.1, P=0.09$; remote: $\left.t_{(8)}=6.6, P<0.001\right)$, followed by a normal extinction on the third retention test (T2 vs. T3: recent: $t_{(5)}=-2.4, P=0.06$; remote: $\left.t_{(8)}=4.1, P<0.001\right)$. Importantly, Sal and Mus animals did not differ during the second and third retention tests for both recent (unpaired $t$-test; $t_{(9)}<1$; Fig. 3C) and remote groups $\left(t_{(14)}<1\right.$; Fig. 3D), indicating that Mus infusion into BLA on the first test induced a transient retrieval deficit.

To insure that the retrieval deficit after BLA inactivation did not simply result from an impairment of avoidance behavior, we examined the innate aversion that rats exhibit toward the inherently aversive taste, quinine. Rats were infused into the BLA 30 min before the presentation of a bottle containing $0.1 \mathrm{mM}$ quinine (Sal, $n=6$; Mus, $n=7$ ). There was a strong avoidance of quinine in both groups (Sal: $1.3 \pm 0.3 \mathrm{~mL}$; Mus: $0.8 \pm 0.2 \mathrm{~mL}$; unpaired $t$-test, $\left.t_{(11)}=1.2, P=0.26\right)$. When plain water was presented immediately after quinine, both groups dramatically increased their consumption (paired $t$-test; $P<0.001$ ) and consumed the same amount of water (Sal: $16.6 \pm 0.9 \mathrm{~mL}$; Mus: $14.0 \pm$ $1.3 \mathrm{~mL}$; unpaired $t$-test, $t_{(11)}=1.7, P=0.12$ ). Therefore, muscimol infusion in BLA did not affect avoidance behavior.

Finally, to evaluate whether the observed memory impairment after Mus infusion might be attributable to state-dependent learning, rats received intra-BLA infusion before acquisition and retrieval of COA (Sal, $n=11$; Mus, $n=15$; Fig. 4A). There was no difference between groups during the days of water baseline (unpaired $t$-test, $t_{(24)}=1$; mean water intake: $16.8 \pm 0.5 \mathrm{~mL}$ ) and all rats drank at least nine of the $10 \mathrm{~mL}$ of scented water during the COA acquisition $\left(t_{(24)}<1\right)$. During the retention test, animals infused with Mus exhibited a significant impairment compared with Sal animals $\left(t_{(24)}=7.4, P<0.001\right.$; Fig. 4B). Therefore, muscimol infusion in BLA did not induce a state-dependent learning.

\section{Discussion}

The aim of these experiments was to precisely delineate which mnemonic phases of COA acquisition are dependent on normal BLA functioning, and to determine whether the BLA is critical for the expression of recent and remote COA memory. We first demonstrated that BLA inactivation before, but not after, the CS presentation is deleterious for COA learning. Moreover, inactivation of the BLA before pre-exposure to the odor prevented LI of COA. Finally, BLA inactivation blocked the retrieval of recent and remote COA memory.

\section{The BLA is necessary for novel odor encoding}

Previous studies have shown COA impairment either after permanent lesion or inactivation of the entire amygdala (BermudezRattoni et al. 1983, 1986). In our first experiment, we delineated the specific stage in which the BLA is involved. Pre-CS inactivation restricted to the BLA altered COA, whereas post-CS inactivation had no effect (Fig. 1). Because Mus induces a complete inhibition of neural activity within 20 min after infusion and sustains for at least 1 h (Martin 1991; Martin and Ghez 1993; Edeline et al. 2002), pre-CS inactivation affected not only the formation of novel odor representation, but also the subsequent phases, i.e., the short-term maintenance of the odor memory trace (until the US takes place), the gastric malaise processing, and the odor-malaise association. However, the absence of effect after post-CS Mus infusion indicates that the BLA is more important for the formation of novel odor representation rather than for the subsequent phases of COA memory formation. Control experiments ruled out the possibility that the memory deficit obtained with pre-CS treatment might be attributable to impaired odor perception or to state-dependent learning (Fig. 4). Concerning the cellular mechanisms involved, we have recently reported that activation of the $\beta$-adrenergic receptor in BLA is critical for COA acquisition, whereas protein synthesis in the amygdala is necessary for COA memory consolidation (Miranda et al. 2007; Desgranges et al. 2008). Interestingly, even if previous studies indicate that the BLA is also required for CTA (Gallo et al. 1992; Yamamoto et al. 1995; Morris et al. 1999; Yasoshima et al. 2000), these cellular mechanisms seem not to be required for CTA. CTA acquisition was not affected by pre-CS blockade of $\beta$-adrenergic receptor in BLA (Miranda et al. 2008), and the blockade of protein synthesis within the BLA did not impair CTA memory consolidation (Bahar et al. 2003). The reason why the BLA seems to play a more critical role in COA than CTA remains to be clearly established, but it could be related to the differential involvement of the insular cortex in this conditioning. Like the BLA, the insular cortex receives gustatory, olfactory, and visceral inputs (Sewards and Sewards 2001) representing another likely site for the association of chemosensory information with toxicosis. However, pharmacological manipulations of the insular cortex impaired CTA memory without affecting COA (Rosenblum et al. 1993; Ferreira et al. 2005; Desgranges et al. 2009). Altogether, these results suggest that even if odor and taste information reach both the BLA and the insular cortex, they would be differentially processed by these structures. Consequently, COA would mainly depend on the BLA (and to a lesser extent on the insular cortex) 
A

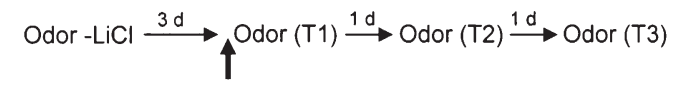

Odor $-\mathrm{LiCl} \stackrel{28 \mathrm{~d}}{\longrightarrow}$ Odor (T1) $\stackrel{1 \mathrm{~d}}{\longrightarrow}$ Odor (T2) $\stackrel{1 \mathrm{~d}}{\longrightarrow}$ Odor (T3)
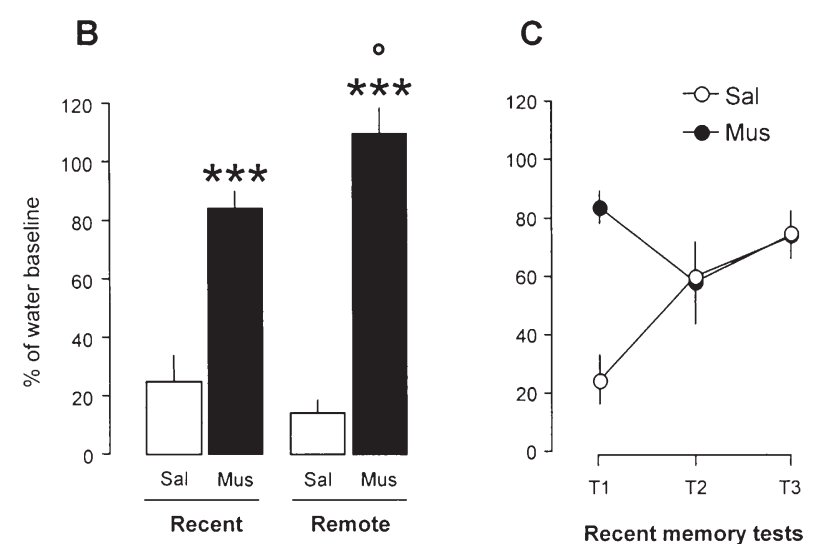

Figure 3. Effects of intra-BLA Mus infusion either before recent ( $3 d$ ) or remote ( $28 d$ ) COA memory test and dynamic of extinction in a drug-free situation. (A) Schematic representation of the time of injection, COA acquisition, memory test, and extinction. (B) Behavioral results of intra-BLA infusion before the first retention test of either recent (left) or remote memory (right). Note that intra-BLA Mus infusion impaired both recent and remote COA memory retrieval. $(C, D)$ Behavioral results for the first memory test with intra-BLA infusion and two other memory tests in a drug-free situation for recent $(C)$ and remote memory $(D)$. Note that animals with intra-BLA Mus infusion matched for control animals for drug-free memory tests. $\left(^{* * *}\right)$ Significantly different from saline-treated groups $(P<0.001) .\left(^{\circ}\right)$ Significantly different from Mus-treated group of the recent memory test $(P<0.05)$.

(see Chapuis et al. 2007b), whereas CTA would preferentially involve the insular cortex (and to a lesser extent the BLA).

To isolate in time the acquisition of odor memory from the association of this odor with the gastric malaise, we also inactivated the BLA before the first presentation of the odor in a LI paradigm. This inactivation prevented LI, i.e., COA was not weakened by odor pre-exposure (Fig. 2). Our results clearly demonstrate that the BLA is involved in both associative and incidental odor learning, and this further contributes to the idea that neuronal activity in the BLA is required for odor encoding (Schoenbaum et al. 1999, 2000; Rosenkranz and Grace 2002). Moreover, our results add to a growing body of evidence indicating that BLA activity is not only required for associative/aversive learning but also for incidental learning, such as taste habituation (Miranda et al. 2008), object recognition (Maroun and Akirav 2008; Roozendaal et al. 2008), or pre-exposure to a neutral stimulus in an LI paradigm (Schauz and Koch 2000; Coutureau et al. 2001; Miranda et al. 2003). In our experiments, the odor was novel when the BLA was inactivated. In order to evaluate whether BLA inactivation interferes specifically with the representation of novel odor, additional experiments would assess the effect of BLA inactivation on COA with familiar odor.

In the present experiment, post-CS inactivation of the BLA did not alter COA. Similarly, we recently showed post-CS blockade of the $\beta$-adrenergic receptor or inhibition of protein synthesis in the BLA did not affect COA (Miranda et al. 2007; Desgranges et al. 2008). Results of the present study suggest that the BLA neural activity is not involved in the short-term maintenance of the CS memory trace, the US processing, and the CS-US association. However, post-CS infusion of the $\mathrm{GABA}_{\mathrm{A}}$ antagonist bicuculline in the BLA rendered COA tolerant to an extended CS-US delay, suggesting the BLA plays an important role in the maintenance of the CS memory (Ferry and Di Scala 1997). However, COA was

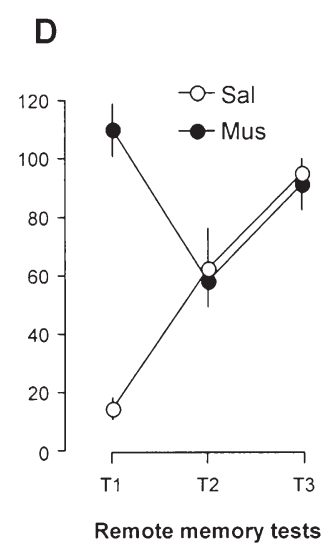

based on ingested odor in our study (inducing primarily retronasal perception), whereas in the Ferry and Di Scala (1997) study, odor was not ingested but delivered on a disc close to the water solution, inducing only orthonasal perception. Therefore, one possibility for explaining this apparent discrepancy is that COA, based on orthonasal perception, relies more on the BLA than COA based on retronasal perception, as previously suggested by neural imaging in humans (Small et al. 2005). Thus, we propose that structures other than the BLA participate in post-CS phases of COA based on ingested odor. The insular cortex could be an interesting candidate as it receives olfactory and visceral projections (Sewards and Sewards 2001), and COA learning induces electrophysiological changes in this structure when COA is based on ingested, but not distal, odor (Chapuis et al. 2007b). Further experiments are needed to clarify the exact role of the BLA and the insular cortex in COA, depending upon the route of odor perception.

\section{The BLA is necessary for the expression of recent and remote odor memory}

We demonstrated that pre-test inactivation of the BLA blocked COA expression 3 and $28 \mathrm{~d}$ after acquisition (Fig. 3). BLA activity is necessary for the expression of a previously learned aversion but not for the expression of an innate aversion (to quinine), indicating that the deficit of COA expression was not attributable to impaired avoidance behavior. Moreover, as previously mentioned, the COA deficit was not the consequence of state-dependent learning (Fig. 4).
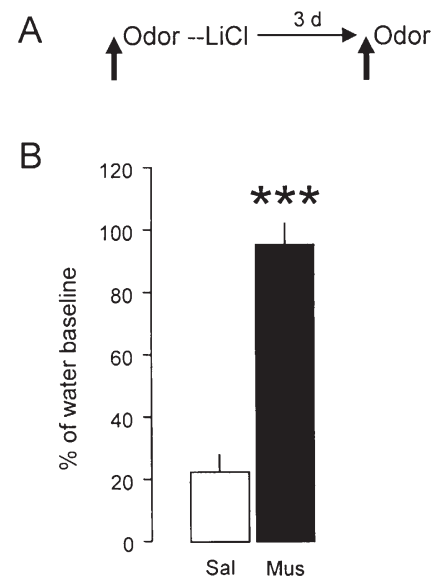

Figure 4. Effects of intra-BLA infusion before the presentation of the CS and before the retention test on COA learning. $(A)$ Schematic representation of the time of injection, COA acquisition, and memory test. (B) Intra-BLA Mus infusion both before COA learning and memory test impaired COA learning. This result indicated that memory impairment was not due to a state-dependent learning. $\left.{ }^{* * *}\right)$ Significantly different from saline-treated group $(P<0.001)$. 
The retrieval impairment does not depend on a noradrenergic system, since we recently demonstrated that BLA infusion of propranolol, a $\beta$-adrenergic antagonist, did not impair expression of recent COA memory (Miranda et al. 2007). The involvement of BLA in the expression of recent memory was previously reported for other aversive tasks, namely, inhibitory avoidance (Liang et al. 1982, 1996; Izquierdo et al. 1997), fear conditioning (Helmstetter 1992; Helmstetter and Bellgowan 1994; Campeau and Davis 1995; Lee et al. 1996; Maren et al. 1996), and CTA (Gallo et al. 1992; Yasoshima et al. 2000). The fact that BLA inactivation abolished COA expression $1 \mathrm{mo}$ after acquisition is also congruent with results obtained in fear conditioning (Lee et al. 1996; Maren et al. 1996; Gale et al. 2004). However, it contrasts with studies on inhibitory avoidance where lesion or pharmacological manipulations of the BLA did not affect the expression of memory older than $10 \mathrm{~d}$ (Liang et al. 1982, 1996; Izquierdo et al. 1997). This indicates that the BLA plays a permanent role in memory expression of fear conditioning and COA, whereas as the memory of inhibitory avoidance matures, its retrieval becomes independent on BLA, and other regions assume a similar integrative function. These differences clearly reflect distinctions in the neural networks sustaining each type of learning and some amygdala circuits that subserve fear conditioning could be shared with COA. This also raises the question of whether the BLA is necessary for remote CTA memory as it is for recent ones (Gallo et al. 1992; Yasoshima et al. 2000).

It must be underlined that BLA manipulations induced a more important deficit in remote than in recent COA memory retrieval. One explanation is that remote memory is weaker than recent memory, and therefore more sensitive to BLA manipulations. However, this seems unlikely because Sal animals exhibited similar or even stronger COA during a remote memory test than during a recent test (for similar findings, see also Chapuis et al. 2007a; Desgranges et al. 2009). Another possibility is that there is a time-dependent reorganization of the neural network sustaining the expression of COA memory, which becomes more dependent on the BLA as the COA memory matures. Similar suggestions have been made for spatial and contextual memories, which are thought to become increasingly dependent on some cortical areas with time (for reviews, see Frankland and Bontempi 2005; Wiltgen et al. 2004; see also Ding et al. 2008 in CTA).

We also showed that in drug-free situations, animals previously treated with Mus exhibited a higher aversion, indicating that inactivation of the BLA did not induce a permanent amnesia, but only a transient COA retrieval deficit. Moreover, during the second test, the animals infused with Mus during the first test exhibited similar aversion as control animals that showed COA extinction compared with the first test. During the third test, all groups exhibited an extinction of learning compared with the second test. These results indicate that inactivation of the BLA during the first test did not prevent learning of COA extinction, as revealed during the subsequent tests. Thus, a normal level of conditioned aversion during the first test is not necessary for extinction learning. To definitely validate this possibility, one interesting perspective would be to inactivate the BLA with Mus before the first and second test, and to evaluate whether extinction will be complete during the third COA memory test. One interesting candidate to sustain COA extinction is the ventromedial prefrontal cortex. This hypothesis is consistent with current models of extinction that involve interactions between several structures, including the BLA and the ventromedial prefrontal cortex for fear conditioning (Quirk et al. 2006; Quirk and Mueller 2008) and CTA extinction (Mickley et al. 2005; Akirav et al. 2006). Further experiments are needed to determine whether the ventromedial prefrontal cortex is involved in COA extinction learning.
In conclusion, combined with recent results indicating that the BLA is a site where consolidation of the COA learning takes place (Desgranges et al. 2008), the BLA appears to acquire, consolidate, and retrieve COA memory. This strongly suggests that BLA is part of a neural network where COA is permanently stored.

\section{Materials and Methods}

\section{Subjects}

Adult male Wistar rats were used (Janvier; 270-320 g at the time of surgery). They were housed individually in polypropylene cages $(34 \times 29 \times 17 \mathrm{~cm})$ lined with abundant pine shavings and kept in a temperature $\left(23^{\circ} \mathrm{C}\right)$ and light $(0700-1900 \mathrm{~h})$ controlled room. All behavioral manipulations were carried out during the light phase, between approximately 1000 and 1200 h. Food and water were provided ad libitum until the beginning of the behavioral procedures. Experiments were performed in accordance with French and European regulations concerning animal experimentation, including authorizations 006352 and A37801 from the French Ministry of Agriculture to perform experiments, and ECC directive 86/609/EEC.

\section{Drugs}

The $\mathrm{GABA}_{\mathrm{A}}$ agonist muscimol (Mus; Sigma) was dissolved in sterile saline $(0.9 \% \mathrm{w} / \mathrm{v})$ to obtain a final concentration of $0.25 \mu \mathrm{g} / 0.25$ $\mu \mathrm{L}$. Vehicle controls received equivolume sterile $0.9 \%$ saline. The dose and volume of Mus was selected on the basis of previous studies investigating the effect of Mus infusion in the BLA on fear memory (Maren et al. 2001; Ponnusamy et al. 2007; Laurent and Westbrook 2008). This concentration $(1 \mu \mathrm{g} / \mu \mathrm{L})$ induces a complete inhibition of neural activity within 20 min after infusion that lasts for at least $1 \mathrm{~h}$ (Martin 1991; Martin and Ghez 1993; Edeline et al. 2002). Based on previous studies, $0.25 \mu \mathrm{g} / 0.25 \mu \mathrm{L}$ of Mus would spread within a radius of $0.5-0.7 \mathrm{~mm}$ from the infusion needle tip (Martin 1991; Arikan et al. 2002; Edeline et al. 2002). Thus, the possibility that Mus spread to adjacent structures, especially the central amygdala nucleus, cannot be completely ruled out. However, lesion studies indicated that the integrity of central amygdala was not essential for COA memory, contrary to that of BLA (Bermudez-Rattoni et al. 1986), suggesting that the effects reported here were primarily located in the BLA.

\section{Surgery and infusion procedure}

Adult rats (50-55 d old) were anesthetized with ketamine (70 mg/ $\mathrm{kg})$ and xylazine $(6 \mathrm{mg} / \mathrm{kg})$ administrated by intraperitoneal injection. They were then implanted with two $17-\mathrm{mm}$ stainlesssteel guide cannulae (23-gauge, Plastic One) using a standard stereotaxic frame (Kopf Instruments). Cannulae were bilaterally implanted into BLA (antero-posterior, $-2.8 \mathrm{~mm}$ relative to Bregma; lateral, $\pm 5.1 \mathrm{~mm}$ from midline; ventral, $-5.5 \mathrm{~mm}$ from dura) (Paxinos and Watson 1998). The tips of the cannulae were aimed $2.0 \mathrm{~mm}$ above the intended area. The cannulae were fixed to the skull with dental acrylic cement and anchored with two surgical screws placed in the skull. Stylets were inserted into the guide cannulae to prevent clogging. Then rats were given $1 \mathrm{wk}$ to recover from surgery.

All animals were handled individually for $\sim 3$ min each day during the last $3 \mathrm{~d}$ before infusion for manipulation habituation. During infusion day, rats were gently restrained by hand, stylets were removed, and injection needles (30 gauge) were inserted, extending $2 \mathrm{~mm}$ from the tip of the guide cannula. The injection needles were connected via polyethylene tubing to two $10-\mu \mathrm{L}$ Hamilton microsyringes driven by an automated microinfusion pump (Harvard Apparatus). A total volume of $0.25 \mu \mathrm{L}$ per hemisphere was delivered over $1 \mathrm{~min}$. After the injections, the needles were left in position for an additional minute to enable diffusion of the solution into the tissue and to minimize dragging of the liquid along the injection track. 


\section{Behavioral procedures}

\section{Conditioned odor avoidance}

COA consists of the association of an odorized tasteless solution (conditioned stimulus, CS) with a visceral malaise (unconditioned stimulus, US). One week after surgery, rats were acclimated to a deprivation regimen for $5 \mathrm{~d}$ and had access to water in a graded bottle (with 0.5 $\mathrm{mL}$ accuracy) in their home cage for $15 \mathrm{~min}$ each day between 0900 and $1100 \mathrm{~h}$. Baseline was obtained by averaging the intake of the three last days. On day 6, animals had access for $15 \mathrm{~min}$ to $10 \mathrm{~mL}$ of almondscented water composed of $0.01 \%$ benzaldehyde (Sigma). This almond solution was chosen as CS because previous studies indicated that its processing is mediated by its odor properties, not by its taste properties (Rusiniak et al. 1979). Indeed, anosmic rats were unable to reliably detect $2 \%$ almond-scented water, whereas they performed as well as control for taste detection (Rusiniak et al. 1979). This provides evidence that this aqueous odorant did not confer any behaviorally detected gustatory sensation to the drinking solution. Therefore, we were confident that $0.01 \%$ almond-scented water served only as an odor cue.

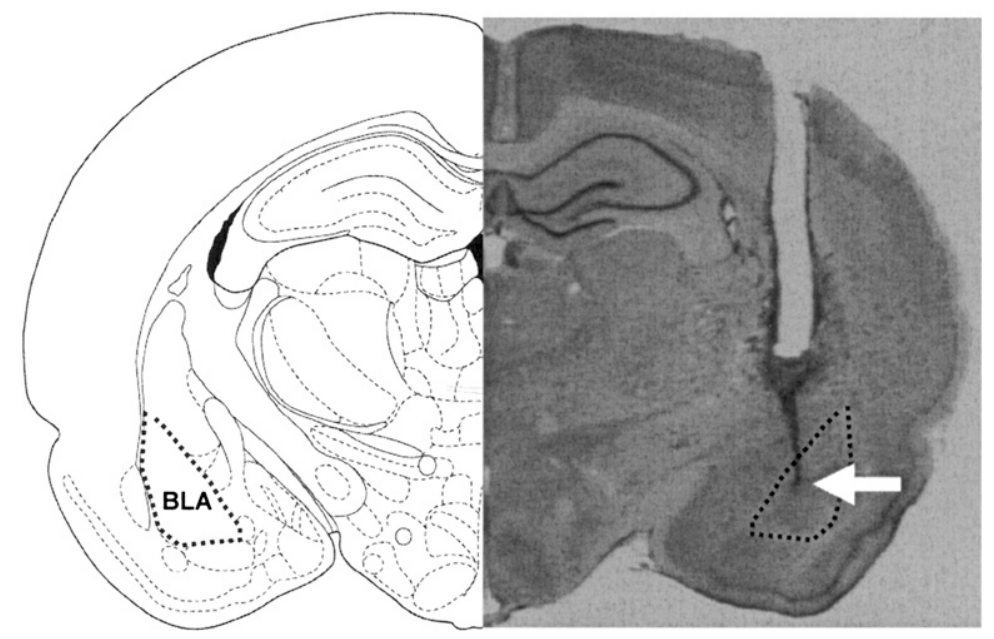

Figure 5. Photomicrograph of representative cannula and the needle track (arrow) terminating in the BLA.

A volume of $10 \mathrm{~mL}$ was chosen because it allows an optimal CS-US association (Barker 1976) and reduces the interindividual variability of liquid consumption induced by intracerebral infusion. Thirty minutes upon termination of the drinking session, the rats received an intraperitoneal injection of the visceral malaise-inducing drug lithium chloride (LiCl, Sigma; 65 $\mathrm{mg} / \mathrm{kg}, 0.15 \mathrm{M}, 10 \mathrm{~mL} / \mathrm{kg}$ ). We recently reported that odor-LiCl pairing in similar conditions induces a strong COA in adult animals (Chapuis et al. 2007a; Miranda et al. 2007; Desgranges et al. 2008; Sevelinges et al. 2009). For the next 2 d, rats had access to water for $15 \mathrm{~min}$ each day in order to reestablish baseline water intake. After these days, odor avoidance was assessed by providing the scented solution for $15 \mathrm{~min}$, immediately followed by $15 \mathrm{~min}$ of water (to evaluate whether treatment altered water ingestion). The percentage of scented water consumption during testing with respect to water baseline consumption was used as a measure of aversion strength.

In a first experiment, rats received bilateral BLA injections of Mus or Sal 30 min before or immediately after CS presentation on the day of COA acquisition and the aversion was tested $3 \mathrm{~d}$ later. In a second experiment, rats received bilateral BLA injections of Mus or Sal immediately before the test performed either $3 \mathrm{~d}$ (recent memory) or $28 \mathrm{~d}$ (remote memory) after COA acquisition. For this experiment, rats underwent two other days of extinction similar to the first test, but without BLA infusion, in order to verify whether animals could express odor avoidance in a drug-free situation.

\section{Latent inhibition of COA}

Previous experiments indicate that substantial latent inhibition can be obtained with only one pre-exposure in CTA (Merhav and Rosenblum 2008) and inhibitory avoidance (Miranda and BermudezRattoni 2007). In this incidental learning paradigm, the procedure was identical to the one described above for COA with the exception that rats had access to $10 \mathrm{~mL}$ of almond solution for 15 min $2 \mathrm{~d}$ before the COA training and odor aversion was assessed 3 $\mathrm{d}$ later. Under this protocol of latent inhibition, pre-exposure to scented water attenuates the acquired aversion to that same odor. Rats were infused with either Mus or Sal into the BLA $30 \mathrm{~min}$ before the pre-exposure to almond-scented water.

\section{Control experiments}

In order to evaluate whether BLA inactivation could have altered odor detection, naïve adult rats were water deprived and then habituated to drink water for $15 \mathrm{~min} /$ day for $5 \mathrm{~d}$. The day after, they were infused with either Mus or Sal into the BLA 30 min before an olfactory detection test. This test lasted $15 \mathrm{~min}$ and consisted of a simultaneous choice between one bottle containing plain water and one containing almond solution (0.01\%) (Bailey and Westbrook 2007). Naïve rats with normal odor detection preferred water over novel scented water (Bailey and Westbrook 2007; Desgranges et al. 2008; Sevelinges et al. 2009). As previously mentioned for COA, anosmic rats were unable to reliably detect $2 \%$ almond-scented water, indicating that $0.01 \%$ almond-scented water served only as an odor cue (Rusiniak et al. 1979). The left/ right position of scented solution alternated between rats, so that half of the rats in each group received almond solution on the left side of the cage and the other half on the right side.

We randomly assigned animals from the previous odordetection task to a second experiment $2 \mathrm{~d}$ later to insure that infusions of Mus into the BLA did not affect the abilities to express aversive behaviors to drinking solution. They were infused with Mus or Sal into the BLA 30 min before presentation of a bottle containing $0.1 \mathrm{mM}$ quinine hydrochloride (Sigma) for $15 \mathrm{~min}$. For rates, this dose of quinine is highly aversive (Yasoshima et al. 2000; Inui et al. 2007). Thereafter, they received $15 \mathrm{~min}$ of water presentation to evaluate the general liquid consumption.

To rule out the possibility that BLA infusion of Mus might induce a state-dependent learning, some rats previously used for post-CS injection and remote memory test were randomly assigned to a second COA training using banana-scented water $(0.01 \%$ isoamyl acetate mixed with water) and received intra-BLA infusions of either Mus or Sal 30 min before training and before test. The banana solution was chosen because previous studies indicated that its processing is mediated by odor, not by any taste properties (Slotnick et al. 1997). Moreover, previous reports indicate that BLA manipulation impaired COA with banana-scented water as CS without affecting banana odor perception (Miranda et al. 2007; Desgranges et al. 2008; Sevelinges et al. 2009).

\section{Histology}

After completion of behavioral experiments, animals were overdosed with sodium pentobarbital (100 mg/kg i.p.) and perfused transcardially with $0.9 \%$ saline. The brains were removed and stored at $4^{\circ} \mathrm{C}$ in a $4 \%$ paraformaldehyde solution for $24 \mathrm{~h}$. The brains were then soaked in a $30 \%$ glucose solution and stored at $4^{\circ} \mathrm{C}$. Coronal sections $(40-\mu \mathrm{M}$ thick) were stained with cresyl violet. Sections were examined microscopically to determine cannula placement. Figure 5 shows a photomicrograph example of the typical cannula tip placement into the BLA. Data from 27 rats were excluded from the statistical analysis because of misplacement of one or both cannulae $(n=22)$ or because BLA infusion induced adipsia $(n=5)$.

\section{Acknowledgments}

This work was supported by AROMALIM Grant Agence National de la Recherche ANR-05-PNRA-002. We thank Claude Cahier and 
Jean-Claude Braguer for the care they provided to the animals during the experiments and Nicole Jouanneau for technical assistance. We also thank Maribel Miranda and Mouna Maroun for comments on a previous draft of this manuscript and Claire Dawson for the English revision of the final text. Y.S. was supported by a post-doc grant from ANR-05-PNRA-002. B.D. was supported by a Ph.D. grant from INRA-Région Centre.

\section{References}

Akirav, I., Khatsrinov, V., Vouimba, R.M., Merhav, M., Ferreira, G., Rosenblum, K., and Maroun, M. 2006. Extinction of conditioned taste aversion depends on functional protein synthesis but not on NMDA receptor activation in the ventromedial prefrontal cortex. Learn. Mem. 13: $254-258$.

Arikan, R., Blake, N.M., Erinjeri, J.P., Woolsey, T.A., Giraud, L., and Highstein, S.M. 2002. A method to measure the effective spread of focally injected muscimol into the central nervous system with electrophysiology and light microscopy. J. Neurosci. Methods 118: 5157.

Bahar, A., Samuel, A., Hazvi, S., and Dudai, Y. 2003. The amygdalar circuit that acquires taste aversion memory differs from the circuit that extinguishes it. Eur. J. Neurosci. 17: 1527-1530.

Bailey, G.K. and Westbrook, R.F. 2007. Within-event learning is disrupted by social isolation immediately after compound exposure. Behav. Brain Res. 178: 313-316.

Barker, L.M. 1976. CS duration, amount, and concentration effects in conditioning taste aversions. Learn. Motiv. 7: 265-273.

Batsell, W.R. and Blankenship, A. 2002. Beyond potentiation: Synergistic conditioning in flavor-aversion learning. Brain Mind 3: 383-408.

Bermudez-Rattoni, F., Rusiniak, K.W., and Garcia, J. 1983. Flavor-illness aversions: Potentiation of odor by taste is disrupted by application of novocaine into amygdala. Behav. Neural Biol. 37: 61-75.

Bermudez-Rattoni, F., Grijalva, C.V., Kiefer, S.W., and Garcia, J. 1986. Flavorillness aversions: The role of the amygdala in the acquisition of tastepotentiated odor aversions. Physiol. Behav. 38: 503-508.

Bures, J. 1998. Ethology, physiological psychology, and neurobiology of conditioned taste aversion. In Conditioned taste aversion, memory of a special kind (ed. J Bures), pp. 1-10. Oxford University Press, New York.

Campeau, S. and Davis, M. 1995. Involvement of the central nucleus and basolateral complex of the amygdala in fear conditioning measured with fear-potentiated startle in rats trained concurrently with auditory and visual conditioned stimuli. J. Neurosci. 15: 2301-2311.

Chapuis, J., Messaoudi, B., Ferreira, G., and Ravel, N. 2007a. Importance of retronasal and orthonasal olfaction for odor aversion memory in rats. Behav. Neurosci. 121: 1383-1392.

Chapuis, J., Messaoudi, B., Ferreira, G., Gervais, R., and Ravel, N. 2007b. Different neural networks involved in conditioned odor aversion learning according to othonasal and retronasal odor presentations. In Society for Neuroscience Abstract 2007, Program number 919.8. Society for Neuroscience, San Diego, CA. http://www sfn org/am2007/.

Coutureau, E., Blundell, P.J., and Killcross, S. 2001. Basolateral amygdala lesions disrupt latent inhibitionin rats. Brain Res. Bull. 56: 4953.

Desgranges, B., Levy, F., and Ferreira, G. 2008. Anisomycin infusion in amygdala impairs consolidation of odor aversion memory. Brain Res. 1236: $166-175$.

Desgranges, B., Sevelinges, Y., Bonnefond, M., Levy, F., Ravel, N., and Ferreira, G. 2009. Critical role of insular cortex in taste but not odor aversion memories. Eur. J. Neurosci. (in press).

Ding, H.K., Teixeira, C.M., and Frankland, P.W. 2008. Inactivation of the anterior cingulate cortex blocks expression of remote, but not recent, conditioned taste aversion memory. Learn. Mem. 15: 290-293.

Edeline, J.M., Hars, B., Hennevin, E., and Cotillon, N. 2002. Muscimol diffusion after intracerebral microinjections: A reevaluation based on electrophysiological and autoradiographic quantifications. Neurobiol. Learn. Mem. 78: 100-124.

Ferreira, G., Ravel, N., Ferry, B., and Levy, F. 2005. Protein synthesis is required in insular cortex for aversive taste memory formation but neither for aversive odour nor for appetitive taste memory in rats. In Society for Neuroscience Abstract 2007, Program number 9198. Society for Neuroscience, San Diego, CA. http://www sfn org/am2007/.

Ferry, B. and Di Scala, G. 1997. Bicuculline administration into basolateral amygdala facilitates trace conditioning of odor aversion in the rat. Neurobiol. Learn. Mem. 67: 80-83.

Frankland, P.W. and Bontempi, B. 2005. The organization of recent and remote memories. Nat. Rev. Neurosci. 6: 119-130.

Gale, G.D., Anagnostaras, S.G., Godsil, B.P., Mitchell, S., Nozawa, T., Sage, J.R., Wiltgen, B., and Fanselow, M.S. 2004. Role of the basolateral amygdala in the storage of fear memories across the adult lifetime of rats. J. Neurosci. 24: 3810-3815.

Gallo, M., Roldan, G., and Bures, J. 1992. Differential involvement of gustatory insular cortex and amygdala in the acquisition and retrieval of conditioned taste aversion in rats. Behav. Brain Res. 52: 91-97.

Garcia, J., Lasiter, P.S., Bermudez-Rattoni, F., and Deems, D.A. 1985. A general theory of aversion learning. Ann. N.Y. Acad. Sci. 443: 8-21.

Helmstetter, F.J. 1992. Contribution of the amygdala to learning and performance of conditional fear. Physiol. Behav. 51: 1271-1276.

Helmstetter, F.J. and Bellgowan, P.S. 1994. Effects of muscimol applied to the basolateral amygdala on acquisition and expression of contextual fear conditioning in rats. Behav. Neurosci. 108: 1005-1009.

Inui, T., Shimura, T., and Yamamoto, T. 2007. The role of the ventral pallidum GABAergic system in conditioned taste aversion: Effects of microinjections of a $\mathrm{GABA}_{\mathrm{A}}$ receptor antagonist on taste palatability of a conditioned stimulus. Brain Res. 1164: 117-124.

Izquierdo, I., Quillfeldt, J.A., Zanatta, M.S., Quevedo, J., Schaeffer, E., Schmitz, P.K., and Medina, J.H. 1997. Sequential role of hippocampus and amygdala, entorhinal cortex and parietal cortex in formation and retrieval of memory for inhibitory avoidance in rats. Eur. J. Neurosci. 9: 786-793.

Lamprecht, R. and Dudai, Y. 2000. The amygdala in conditioned taste aversion: It's there but where? In The Amygdala (ed. J. Aggleton), pp. 310-331. Oxford University Press, New York.

Laurent, V. and Westbrook, R.F. 2008. Distinct contributions of the basolateral amygdala and the medial prefrontal cortex to learning and relearning extinction of context conditioned fear. Learn. Mem. 15: 657-666.

Lee, Y., Walker, D., and Davis, M. 1996. Lack of a temporal gradient of retrograde amnesia following NMDA-induced lesions of the basolateral amygdala assessed with the fear-potentiated startle paradigm. Behav. Neurosci. 110: 836-839.

Liang, K.C., McGaugh, J.L., Martinez Jr., J.L., Jensen, R.A., Vasquez, B.J., and Messing, R.B. 1982. Post-training amygdaloid lesions impair retention of an inhibitory avoidance response. Behav. Brain Res. 4: 237-249.

Liang, K.C., Hu, S.J., and Chang, S.C. 1996. Formation and retrieval of inhibitory avoidance memory: Differential roles of glutamate receptors in the amygdala and medial prefrontal cortex. Chin. J. Physiol. 39: 155166.

Maren, S., Aharonov, G., and Fanselow, M.S. 1996. Retrograde abolition of conditional fear after excitotoxic lesions in the basolateral amygdala of rats: Absence of a temporal gradient. Behav. Neurosci. 110: 718-726.

Maren, S., Yap, S.A., and Goosens, K.A. 2001. The amygdala is essential for the development of neuronal plasticity in the medial geniculate nucleus during auditory fear conditioning in rats. J. Neurosci. 21: RC135:1-6.

Maroun, M. and Akirav, I. 2008. Arousal and stress effects on consolidation and reconsolidation of recognition memory. Neuropsychopharmacology 33: $394-405$.

Martin, J.H. 1991. Autoradiographic estimation of the extent of reversible inactivation produced by microinjection of lidocaine and muscimol in the rat. Neurosci. Lett. 127: 160-164.

Martin, J.H. and Ghez, C. 1993. Differential impairments in reaching and grasping produced by local inactivation within the forelimb representation of the motor cortex in the cat. Exp. Brain Res. 94: 429443.

McGaugh, J.L. 2004. The amygdala modulates the consolidation of memories of emotionally arousing experiences. Annu. Rev. Neurosci. 27: $1-28$.

Merhav, M. and Rosenblum, K. 2008. Facilitation of taste memory acquisition by experiencing previous novel taste is protein-synthesis dependent. Learn. Mem. 15: 501-507.

Mickley, G.A., Kenmuir, C.L., Yocom, A.M., Wellman, J.A., and Biada, J.M. 2005. A role for prefrontal cortex in the extinction of a conditioned taste aversion. Brain Res. 1051: 176-182.

Miranda, M.I. and Bermudez-Rattoni, F. 2007. Cholinergic activity in the insular cortex is necessary for acquisition and consolidation of contextual memory. Neurobiol. Learn. Mem. 87: 343-351.

Miranda, M.I., LaLumiere, R.T., Buen, T.V., Bermudez-Rattoni, F., and McGaugh, J.L. 2003. Blockade of noradrenergic receptors in the basolateral amygdala impairs taste memory. Eur. J. Neurosci. 18: 26052610.

Miranda, M.A., Ferry, B., and Ferreira, G. 2007. Basolateral amygdala noradrenergic activity is involved in the acquisition of conditioned odor aversion in the rat. Neurobiol. Learn. Mem. 88: 260-263.

Miranda, M.I., Rodriguez-Garcia, G., Reyes-Lopez, J.V., Ferry, B., and Ferreira, G. 2008. Differential effects of $\beta$-adrenergic receptor blockade in basolateral amygdala or insular cortex on incidental and associative taste learning. Neurobiol. Learn. Mem. 90: 54-61.

Morris, R., Frey, S., Kasambira, T., and Petrides, M. 1999. Ibotenic acid lesions of the basolateral, but not the central, amygdala interfere with conditioned taste aversion: Evidence from a combined behavioral and anatomical tract-tracing investigation. Behav. Neurosci. 113: 291302 . 
Palmerino, C.C., Rusiniak, K.W., and Garcia, J. 1980. Flavor-illness aversions: The peculiar roles of odor and taste in memory for poison. Science 208: 753-755.

Paxinos, G. and Watson, C. 1998. The rat brain in stereotaxic coordinates. Academic Press, New York.

Phelps, E.A. and LeDoux, J.E. 2005. Contributions of the amygdala to emotion processing: From animal models to human behavior. Neuron 48: $175-187$.

Ponnusamy, R., Poulos, A.M., and Fanselow, M.S. 2007. Amygdaladependent and amygdala-independent pathways for contextual fear conditioning. Neuroscience 147: 919-927.

Quirk, G.J. and Mueller, D. 2008. Neural mechanisms of extinction learning and retrieval. Neuropsychopharmacology 33: 56-72.

Quirk, G.J., Garcia, R., and Gonzalez-Lima, F. 2006. Prefrontal mechanisms in extinction of conditioned fear. Biol. Psychiatry 60: 337-343.

Reilly, S. and Bornovalova, M.A. 2005. Conditioned taste aversion and amygdala lesions in the rat: A critical review. Neurosci. Biobehav. Rev. 29: 1067-1088.

Roozendaal, B., Castello, N.A., Vedana, G., Barsegyan, A., and McGaugh, J.L. 2008. Noradrenergic activation of the basolateral amygdala modulates consolidation of object recognition memory. Neurobiol. Learn. Mem. 90: 576-579.

Rosenblum, K., Meiri, N., and Dudai, Y. 1993. Taste memory: The role of protein synthesis in gustatory cortex. Behav. Neural Biol. 59: 49-56.

Rosenkranz, J.A. and Grace, A.A. 2002. Dopamine-mediated modulation of odour-evoked amygdala potentials during pavlovian conditioning. Nature 417: 282-287.

Rusiniak, K.W., Hankins, W.G., Garcia, J., and Brett, L.P. 1979. Flavor-illness aversions: Potentiation of odor by taste in rats. Behav. Neural Biol. 25: 1-17.

Schauz, C. and Koch, M. 2000. Blockade of NMDA receptors in the amygdala prevents latent inhibition of fear-conditioning. Learn. Mem. 7: 393-399.
Schoenbaum, G., Chiba, A.A., and Gallagher, M. 1999. Neural encoding in orbitofrontal cortex and basolateral amygdala during olfactory discrimination learning. J. Neurosci. 19: 1876-1884.

Schoenbaum, G., Chiba, A.A., and Gallagher, M. 2000. Changes in functional connectivity in orbitofrontal cortex and basolateral amygdala during learning and reversal training. J. Neurosci. 20: 5179_ 5189.

Sevelinges, Y., Levy, F., Mouly, A.M., and Ferreira, G. 2009. Rearing with artificially scented mothers attenuates conditioned odor aversion in adulthood but not its amygdala dependency. Behav. Brain Res. 198: 313320 .

Sewards, T.V. and Sewards, M.A. 2001. Cortical association areas in the gustatory system. Neurosci. Biobehav. Rev. 25: 395-407.

Slotnick, B.M., Westbrook, F., and Darling, F.M.C. 1997. What the rat's nose tells the rat's mouth: Long delay aversion conditioning with aqueous odors and potentiation of taste by odors. Anim. Learn. Behav. 25: 357-369.

Small, D.M., Gerber, J.C., Mak, Y.E., and Hummel, T. 2005. Differential neural responses evoked by orthonasal versus retronasal odorant perception in humans. Neuron 47: 593-605.

Wiltgen, B.J., Brown, R.A., Talton, L.E., and Silva, A.J. 2004. New circuits for old memories: The role of the neocortex in consolidation. Neuron 44: 101-108.

Yamamoto, T., Fujimoto, Y., Shimura, T., and Sakai, N. 1995. Conditioned taste aversion in rats with excitotoxic brain lesions. Neurosci. Res. 22: 31-49.

Yasoshima, Y., Morimoto, T., and Yamamoto, T. 2000. Different disruptive effects on the acquisition and expression of conditioned taste aversion by blockades of amygdalar ionotropic and metabotropic glutamatergic receptor subtypes in rats. Brain Res. 869: 15-24.

Received September 30, 2008; accepted in revised form January 11, 2009. 


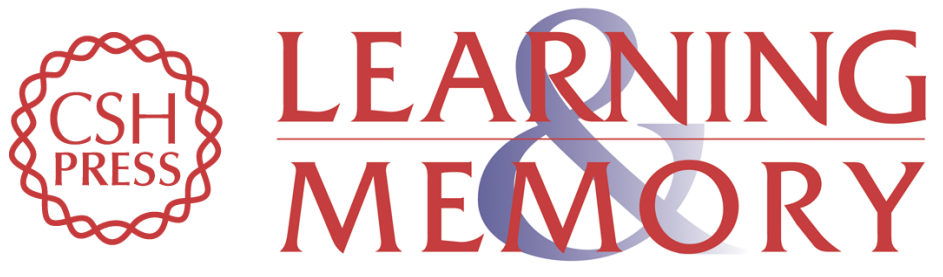

\section{The basolateral amygdala is necessary for the encoding and the expression of odor memory}

Yannick Sevelinges, Bertrand Desgranges and Guillaume Ferreira

Learn. Mem. 2009, 16:

Access the most recent version at doi:10.1101//m.1247609

References This article cites 60 articles, 10 of which can be accessed free at:

http://learnmem.cshlp.org/content/16/4/235.full.html\#ref-list-1

License

Email Alerting Receive free email alerts when new articles cite this article - sign up in the box at the Service top right corner of the article or click here. 